\title{
Cycling, the Built Environment, and Health: Results of a Midwestern Study
}

\section{Citation}

Forsyth, Ann, and J. Michael Oakes. 2014. "Cycling, the Built Environment, and Health: Results of a Midwestern Study." International Journal of Sustainable Transportation 9 (1) (July 17): 4958. doi:10.1080/15568318.2012.725801. http://dx.doi.org/10.1080/15568318.2012.725801.

\section{Published Version}

doi:10.1080/15568318.2012.725801

\section{Permanent link}

http://nrs.harvard.edu/urn-3:HUL.InstRepos:17462968

\section{Terms of Use}

This article was downloaded from Harvard University's DASH repository, and is made available under the terms and conditions applicable to Open Access Policy Articles, as set forth at http:// nrs.harvard.edu/urn-3:HUL.InstRepos:dash.current.terms-of-use\#OAP

\section{Share Your Story}

The Harvard community has made this article openly available.

Please share how this access benefits you. Submit a story.

Accessibility 
Cycling, the Built Environment, and Health: Results of a Midwestern Study

A. Forsyth and J.M. Oakes

International Journal of Sustainable Transportation 15, 1: 49-58

2015 


\begin{abstract}
Are cyclists different from those who do not cycle in terms of individual and neighborhood characteristics? This paper draws on a study of over 700 adults in three groups: those who had cycled in the past week, in the past 2 years, and non-cyclists. It examines their body mass index (BMI), physical activity, socio-demographics, environmental perceptions, and geographic information system (GIS)-measured neighborhood features. Those who cycled occasionally lived in similar environments to frequent cyclists but perceived some aspects differently. Those who cycled more demonstrated characteristics generally thought to indicate good health, but they did not perceive themselves as healthier.
\end{abstract}




\section{Introduction}

Getting around by using personal power such as walking or cycling is an area of some interest in transportation, urban design, and public health. Transportation has a vibrant literature on such issues as cycling infrastructure, safety, and the commute to work. Most research that looks at the intersection between health and active or non-motorized transportation has, however, focused on walking. This is partly because more people walk than cycle although the ratio varies by location. This paper fills some of this gap by exploring two issues. First is whether frequent cyclists are different from those who cycle infrequently, or not at all, with regard to individual characteristics including health-related topics. The second is whether those with different levels of cycling differ in terms of the environments in which they reside and in how they perceive those environments.

This study exploring environmental and health related differences between frequent, occasional, and non-cyclists is important for the field of sustainable transportation for three reasons. First, this is one of the first studies of adult cycling and environments to look in depth at health-relevant measures (perceived health, body mass index [BMI], and total physical activity [PA]). Second, the paper also examines the relationship between the broader built environment and amounts of cycling, something of great interest among those aiming to promote nonmotorized modes. It focuses on larger "community design" features-such as density, land use, and block size-along with the perceived environment, complementing the many previous studies of bicycle infrastructure. Third, as well as frequent cyclists and noncyclists, the paper analyzes characteristics of the group of occasional cyclists who may be targeted in proposals to increase cycling.

Many studies in public health that examine associations between environments and active travel use the social-ecological model, a broad theory aiming to capture the variety of influences on health outcomes-biological, psychological, behavioral, social, and environmental. These influences operate at different scales from the body to the region (Stokols 1992; Giles-Corti and Donovan 2002). Such models may also include organizational contexts and policies as part of the larger environment (McLeroy 1988). These theories have become popular replacements of psychosocial theories that omitted environment (and to an extent, biology) and environmental theories that took too little account of social concerns and individual behaviors. Social ecological theory would suggest, for example, that the decision to cycle is influenced in varying degrees by biological traits (e.g. sense of balance), individual perceptions and behaviors (e.g. the decision to ride for exercise because it is healthy), social contexts (whether cycling is perceived as "hip"), and environmental contexts (whether destinations are close enough or there are enough safe routes).

However, transportation research also brings a useful set of theories to apply to decisions about cycling for transportation. Many in transportation research, drawing on economics, propose that individuals choose to cycle if the benefits outweigh the costs (utility maximization). Costs have traditionally been estimated in terms of time and money, however such theories have been extended to take account of personal preferences, household interactions, social networks, and other supports and barriers (Handy 2005; Krizek et al. 2009). According to such conceptualizations, because cycling is often slower than driving but is typically less expensive people will cycle if their time is of relatively low value. However, if someone perceives cycling as good for health then (up to a point) the time taken cycling is also 
a benefit. Conversely if people lack support for cycling (e.g. a lack of bike storage at work) costs will be higher.

For those looking at potential interventions to increase cycling as a healthy behavior it is important to find points of leverage, for example types of people who might be encouraged to cycle more. One possible group for investigation is those who cycle from time to time who may be more likely to increase their cycling than those who do not cycle at all. They have demonstrated they know how to cycle, have gained access to a bicycle, and have found places to cycle. Understanding how infrequent or occasional cyclists compare with both those who cycle a lot and those who never cycle might indicate points of intervention (e.g. environmental changes, or topics for educational campaigns). Of course even if occasional cyclists engage in more cycling they may merely do less of other forms of physical activity (e.g. walking or playing sports) cancelling out any health benefit. It is quite possible that there is some sort of physical activity budget (Rodriguez et al. 2006).

\subsection{Background}

While the health effects of cycling can be an important factor in deciding whether to promote the mode, most work looking at the intersection of transportation and health has focused on accidents and injuries (e.g. Jacobsen 2003). Relatively few studies of transportation cycling have measured more general health-related characteristics such as body mass index, perceived health, or total physical activity. An interesting exception is Wen and Rissel's (2009) multivariate assessment of a survey of 6,810 Australian workers. They found men who cycled or took public transportation to work were less likely to be obese than drivers, but these relationships were not significant for women. Such work extends earlier studies that looked at population-level data and found that in places with higher participation rates for cycling respondents had lower BMIs (Bassett et al., 2008). More qualitatively, a study based on indepth interviews with 31 cyclists and non-cyclists in Davis (California) and Delft (Netherlands) found the vast majority perceived cycling as healthy (Heinen and Handy, 2011). In an interview and focus group study of women cyclists in Adelaide, Australia, older women particularly mentioned the health benefits (Bonham and Wilson, 2012).

In recent years there also has been growing interest in associations between the built environment and cycling, with particular attention being paid to the design of cycling facilities and networks. While there is debate regarding the safety of separated bicycle trails and lanes, several reviews have proposed that on balance, to increase cycling a place needs some forms of special cycling infrastructure, such as lanes and parking, organized into a continuous network, and combined with education and programming (Dill, 2009; Forsyth and Krizek, 2010; Heinen et al., 2010; Pucher et al., 2010; Yang et al., 2010). Communities with these multiple cyclingsupportive features may attract more cyclists who also increase the amount of cycling in the area (Xing et al., 2010).

Less is known about cycling and overall community design or the larger pattern of development including such topics as land use mix and density, a focus of the analysis in this paper. This is made more complicated in that cycling occurs for different purposes-broadly exercise/recreation and transportation-but many trips combine purposes e.g. cycling to the store for exercise, or cycling along a trail to meet friends. While proximity to destinations (a community design feature) may be important for transportation purposes, those interested in 
exercise may deliberately pick longer routes. Such multi-purpose trips are a challenge for reporting and analysis.

For this reason many studies consider cycling in general, mixing purposes. Moudon et al. (2005) examined self-report data from 608 respondents, 21 percent of whom had cycled in the last week typically, but not always, for recreation or exercise. Some of the many environmental features they measured using a geographical information system (GIS) in $3 \mathrm{~km}$ buffers around participant residences appeared correlated with cycling. These features included distance to the closest trail and measures of several destinations (less area taken up by convenience stores; more offices, fast-food restaurants, hospitals, and multi-family housing). However, the authors found that overall cycling was only "moderately associated with the neighborhood environment;" cycling instead seemed to reflect individual choices (pp. 245, 257).

Similarly, Noland et al. (2011) conducted on a survey of 736 bicycle riders (who had ridden in the last six months, a majority for recreational purposes) and 1,283 non riders in New Jersey. They found that in predicting cycling, demographic and socioeconomic factors were more powerful than place-based ones, measured at the zip code level (also Cervero and Duncan, 2003; Kamphuis et al. 2008).

Others have found similar results in studies focused on utilitarian cycling. Cervero et al. (2009) surveyed 1,500 respondents in Bogota using the International Physical Activity Questionnaire (IPAQ), which measures cycling in bouts of more than 10 minutes to get from place to place and is described in more detail later in this paper. Respondent neighborhoods were assessed via GIS using $500 \mathrm{~m}$ buffers and also larger neighborhoods. GIS variables included measures of density, land use mix, amenities, design, safety, and accessibility to destinations and transit. The only larger urban design-type variable related to utilitarian cycling was the density of streets. The more cyclist-specific variable of route connectivity was also important. Owen et al. (2010) also used the IPAQ to examine cycling in Adelaide $(\mathrm{N}=1,940)$ and Ghent ( $\mathrm{N}=372$ ). They found somewhat more cycling in areas that scored highly on a walkability index measured using GIS variables in Australia and perceived variables in Ghent.

Studies of more specific purposes, such as commuting to work, find stronger associations e.g. with distance (Handy and Xing, 2010). Others have studied perceived environments finding perceived safety problems and long distances negatively affecting transportation cycling (Dill and Voros, 2007; Xing et al., 2010; Akar et al., 2012). All told there is still a need to investigate links between cycling, health, and environments. Such investigations can enrich debates about social aspects of sustainable transportation modes.

\section{Material and Methods}

\subsection{Study Design}

This study uses data collected from the Twin Cities Walking Study (TCWS). The TCWS was a uniquely designed study conducted in 2004 in the Minneapolis-St. Paul area of Minnesota; details of methods have been reported elsewhere (Forsyth et al. 2007, 2008; Oakes et al. 2007; Sirard et al. 2011). The study team recruited 716 participants aged 24 or more; 703 of these had complete cycling data. Of these $73(11 \%)$ had cycled for any purpose in the last week and 346 (50\%) more responded that they had cycled in the neighborhood in the last 2 years but not the last week. 
Respondents lived in 36 different $805 * 805$ meter $(0.5 * 0.5$ mile) focus areas or neighborhoods, selected to be environmentally diverse along the dimensions of block size and population density, features associated with travel walking according to earlier research. The study team initially identified approximately 130 such areas in a part of the Minneapolis-St. Paul metropolitan area that had particularly rich GIS data at the time of the study and that stretched from the urban core in St. Paul to the urban fringe. These areas were divided into three in terms of median block size (small [less than 2ha], medium, and large [more than 5ha]) and gross population density (high [more than 24.7 persons/ha], medium, and low [less than $12.4 /$ ha]). Specific study areas $(\mathrm{N}=36)$ were chosen by randomly sampling from the four most extreme types: big blocks/high density; big blocks/low density, and so on.

The size of the focus areas was picked because it represented a uniform and relatively small walkable neighborhood of a half mile square where fieldwork could be conducted. While the study team did assess the focus areas, measurements were also conducted for a set of buffers around individual participants, including 200,400, 800, and 1,600 meter straight-line and street network buffers (using ESRI Network Analyst ArcView 3.3). It is these individual buffers that are used in this analysis.

Respondents were aged 24 or older, in town the week of the survey, and able to walk unaided for at least 20 minutes. To avoid seasonal biases approximately equal numbers of participants were recruited from each area in four two-month long "waves" throughout an 8month period of warmer weather (April to November) (Forsyth et al. 2007; Oakes et al. 2009). Participants were contacted via mailed letters and telephone calls (where phone numbers were available) in the context of a media campaign that raised local awareness of the study. The majority (74 percent) of respondents were randomly selected through these means. Other participants were recruited from specific areas through postcards and fliers (mailed, distributed at local meetings, and handed out on the relevant streets). This continued until there were 20 people recruited from each focus area. Compared with census data those in the random sample were of slightly higher socio-economic status (SES) and those from the "volunteer" group of slightly lower SES. Overall sample demographics were fairly similar to census profiles (Oakes et al., 2009). Recruitment strategies have been reported in detail elsewhere (Oakes et al. 2009).

Participants had their height and weight measured; wore MTI Actigraph accelerometers or motion detectors for a week (MTI Inc., Fort Walton Beach, FL); kept travel diary records for the same week; and at the end of the week answered survey questions over the phone following along with a printed copy of the survey. Accelerometers were used because they reliably measure total physical activity (Sirard et al. 2011). The travel diary was modeled on the National Household Travel Survey in the U.S., though modified to last one week and to include walking and cycling loop trips (starting and ending in the same point). The survey included the International Physical Activity Questionnaire long form for the last seven days (IPAQ-LF) and the full survey is available online (Twin Cities Walking Survey 2004). The IPAQ measures many domains of physical activity including activities related to jobs, transportation, housework, recreation and sport, and time spent sitting. In order to obtain information on reliability of all measures, approximately 20 percent of participants repeated measures with reliability information published for the survey and accelerometer (Forsyth et al. 2009, Sirard et al. 2011).

The survey also included questions about the perceived environment and demographics. The perceived environment questions covered a number of topics and were grouped into scales 
related to: perceived access to services ( 6 items on local shopping, destinations, hills, transit), places for walking and cycling ( 3 items on sidewalks and trails), neighborhood surroundings/attractiveness ( 6 items on trees, shade, attractiveness, litter), traffic safety (2 items), safety from crime ( 6 items dealing with lighting, visibility, perceived crime), neighborhood satisfaction (16 items from local friends to restaurants and schools), social cohesion ( 5 items on neighbors helping, trust, shared values), social life/neighboring ( 9 items to do with waving, saying hello, visiting, asking for help and advice, etc.), and social life/collective action ( 8 items related to working together or taking action to achieve neighborhood aims and stop problems).

The built environment was measured using existing land use and business databases, aerial photo interpretation, and fieldwork, and processed using the ArcGIS suite of software (Esri, Redlands CA). The measurement protocols describing how each variable was developed and measured are available online (Forsyth 2005).

\subsection{Measures: Cycling}

Cycling was measured in three ways.

- The IPAQ, used as part of the larger survey, asked "During the last 7 days, on how many days did you use a bicycle for at least $\mathbf{1 0}$ minutes at a time to go from place to place?" It then went on to ask how much time the person usually spent on one day. Total travel cycling can be calculated through multiplying the number of days by the usual time and is reported in MET minutes which are a measure of exercise intensity by duration (Centers for Disease Control 2006a, 2006b). Other parts of the survey asked about cycling for exercise but in questions combined with other forms of activity so not useable in this analysis.

- The travel diary asked participants to record all trips between two places, as well as recreational loops, with distances recorded in miles or blocks. While the purpose of each trip was recorded, in many cases it was difficult to distinguish between recreational and travel cycling so in this analysis we focus on total distance cycled.

- The survey also asked if people had cycled in their neighborhood in the past two years and then to state the most recent time they had ridden (see discussion below). While this question focused on neighborhood cycling, related to the environments that were being measured, the other questions about cycling did not limit location.

The responses to the methods of asking about cycling did not all agree. Thirty-six people said in the survey they had ridden in the last week but had not recorded that in their diarieswe put them in the less frequent cyclist group (those who had ridden in the past two years); five people did not report riding in the neighborhood but did have cycle miles so we included them with frequent cyclists. As noted below a few people also reported cycling in the IPAQ but not the diary. The diary and survey responses for the other people coincided. We use these questions to allocate people to three groups: frequent cyclists (those with entries for cycling in the travel diary), infrequent or occasional cyclists (who had cycled in the last two years according to the survey but did not have cycling in their diaries), and non-cyclists (those who had not cycled in the past two years).

The study was approved by the University of Minnesota's Institutional Review Board for the protection of human research subjects. 


\section{Analyses}

Analyses begin with a comparison of socio-demographic characteristics of various categories of cyclists testing differences with t-tests and Chi-square as appropriate given the character of the data. We then examine the relationship between measured and perceived environmental features and cycling distance using bivariate Pearsons correlations. Because of the large number of associations tested and the threat of Type I errors we use two thresholds of statistical significance for correlations, $p<0.05$ and $p<0.01$. Further descriptive statistics compare cyclist status (frequent cyclist, occasional cyclist, and non-cyclist) in terms of residential environments-both measured and perceived. Multiple regression models explore the relationship between cycling distance and health-related characteristics, adjusting first for socio-demographic variables and then adding in an environmental feature. Because of skewed outcomes, we use negative binomial regressions when we assess total physical activity (measured by accelerometer) and linear models (i.e., OLS) when assessing BMI and perceived health. Because participants came from 36 neighborhoods we use clustered standard errors in all regression models - a form of GEE models. All analyses were conducted in Stata, version 12 SE.

\section{Results}

Table 1 presents comparisons for the three study groups: frequent cyclists, infrequent or occasional cyclists, and non-cyclists. We also compare these groups in two ways-cyclists vs. non-cyclists (columns $A+B$ vs. column $C$ ) and frequent cyclists vs. others ( $A$ vs. $B+C$ ). Compared with non-cyclists, people who cycled at all were more likely to be married, own a home, be younger, and have larger households. Recent cyclists were more likely than others to be male. Both pairs of comparisons have statistically significant differences in miles cycled (unsurprising given the criteria used to allocate people to groups), accelerometer counts (a measure of total physical activity with those cycling more doing more physical activity), education (higher among those who cycled more), length of time in one's home (non-cyclists had the longest periods), perceived health (higher among those who cycled more in these bivariate assessments), and body mass index (lower among those who cycled more). None of these are surprising with the possible exception of years living in one's home which may be a proxy for age, with older people being more likely to have lived in their homes longer and less likely to cycle.

\section{INSERT TABLE 1 HERE}

Those who had more miles in their diary also reported doing more cycling for transportation in the IPAQ survey though it should be noted that 12 people without miles in their diary reported IPAQ cycling (which is why column B in the IPAQ row is not equal to zero). This inconsistency may be due to slight differences in the time period of reporting-for example the participant completing their diary on a Wednesday and doing the interview on a Thursday. It may also be due to problems recalling the past which is why we more often use the diary for analyses as it was recorded on the day of activity. Not reported in the table, respondents on average had 1.7 bicycles in their household but those who had cycled in the last week had 2.6. 
There were no significant differences across the three groups between the numbers that had been randomly recruited and those recruited by other means.

A series of questions asked about neighborhood cycling condition. Among all respondents, $60 \%$ (418) had ridden in the past two years in their neighborhood. Of those who had cycled in the past two years, including those who had done so in the past week, 36 had felt threatened on the last day they had done so; of frequent cyclists the number was 7 . The top threats were motorists (79\%), uneven walkways or road surfaces $(58 \%)$, and the potential for crime (39\%). Participants were also asked how satisfied they were with how their local community is designed for making bike riding safe and a substantial minority, 20 percent, were somewhat or very dissatisfied. Most respondents wanted more off road bike paths and trails (74\%) as well as more on road bike lanes (76\%) but responses were mixed about whether to allow cyclists on sidewalks ( $28 \%$ wanting them and $23 \%$ not).

Pearson correlations are used to test associations between miles cycled and the 43 environmental features elaborated in the GIS protocols for the project (Forsyth 2005) (Table 2). Seven measures related to density including variations on residential population, employee, and housing unit densities as well as lot coverage. Ten measures related to street patterns or connectivity including measures of block area and perimeter, access points, road length, connected node ratios, and measures of intersection density and type. Seventeen measures were of land uses including the percentage of parcel areas in 10 different land uses from autooriented to retail, mixed use indices, and densities of various types of retail employees. Finally, nine measures dealt with infrastructure including sidewalks, street lights, street trees, transit stops, and field-based measures of crossings, traffic calming, and litter/graffiti. As mentioned earlier, the study measured 200,400,800, and 1,600 meter straight-line and street network buffers around individuals. Due to data availability issues, however, some variables were only measured using the smaller buffers (employment densities, land use indices, and infrastructure apart from street lights and transit stops).

\section{INSERT TABLE 2 HERE}

In this study we examine associations with travel cycling measured by the IPAQ survey, that focused on riding to get around. All correlations are quite smalland only three that reach statistical significance at the $p<0.05$ level and none at the more conservative $p<0.01$ level. More cycling occurred where people lived near industrial, and industrial /auto-oriented land uses, and in areas with visible litter and graffiti. The two industrial land use measures came from different sources - the first from metropolitan wide generalized land use data (using both aerial photography and assessors' data) and the second from much finer-gained county and city parcel information. The litter, graffiti, and dumpster variable was based on fieldwork using the Irvine Minnesota Inventory (Boarnet et al. 2006; Day et al. 2006). There are also significant associations with total miles cycled measured by the diary, and including both travel and recreational cycling. These involve four measures of density as well as park area and the litter measure. However, only one land use variable-parks and recreation percentage-reaches significance at the $p<0.01$ level and then only at one buffer size $(1600 \mathrm{~m})$.

The findings indicate that people in areas with lower densities and more parks cycled more. Although the associations are very modest, those looking to use inexpensive and/or 
active transportation modes may find cycling to be more viable than walking given distances in low-density areas; low density areas and locations with parks may also provide less congested areas for recreational cycling. The litter measure was positively associated with cycling using both cycling measures. This is perhaps a proxy for lower-income neighborhoods where cycling may be seen an inexpensive mode or for more congested urban areas where cycling may compete in speed with autos. Given the large number of variables tested, however, these results should be interpreted with caution.

We further examine whether frequent cyclists, occasional cyclists, and non-cyclists lived in different kinds of neighborhoods, comparing environmental features around their homes and testing differences between them using ANOVA. We analyze 43 different environmental features mentioned above, mostly for 1,600 meter network buffers (measured using ESRI Network Analyst ArcView 3.3) except where only smaller buffers were available. The thirteen variables with significant differences between the groups $(p<0.05)$ are described in Table 3. A number of density measures show significant differences among groups with non-cyclists living in higher-density areas where buildings covered more of the lot. The two measures of industrial land use again show significant differences with non-cyclists living in areas with the most of these and also in areas with the most dissimilar land uses. In addition a number of street pattern measures have significant differences. Non-cyclists lived in the areas with the smallest blocks. They also lived in areas with more sidewalks and transit stops. If a more conservative test of significance of $p<0.01$ is used, only about half these associations would remain, however. In terms of magnitude, all associations are very small.

\section{INSERT TABLE 3 HERE}

Overall Table 3 indicates cyclists - both frequent and occasional cyclists--living in areas with similar characteristics. They had lower densities, larger blocks, fewer sidewalks, and fewer bus stops. Such areas are often found in suburban locations but may also occur in some outer parts of core cities. Conversely, non-cyclists lived in areas with many features seen as promoting walking for transportation even though they walked fewer miles per day than cyclists according to their travel diaries.

Because the perceived and actual environments are often quite different, we also examine whether perceptions differed among the groups, testing nine different scales each composed of two to 16 items as is described earlier (see Table 4). Six show significant differences among frequent, occasional, and non-cyclists: perceived access to services, places for walking and cycling, neighborhood surroundings, safety from crime, neighborhood satisfaction, and the social life/neighboring scale. In each case those who cycled more saw the neighborhood more positively though a cross sectional study cannot determine if this positive view was a result of their cycling or a cause of it. Three scales show no significant differences among the groups - traffic safety, social cohesion, and social life/collective action scale.

\section{INSERT TABLE 4 HERE}

We next explore whether these associations between distance cycled measured by diary and three outcome measures (perceived health, total PA, and body mass index), identified in 
Table 1, hold when adjusting for socioeconomic variables (see Table 5). These variables include sex, race, education, marital status, home ownership, car ownership, age, and household size. We present regression coefficients.

- In these multivariate assessments, cycling was not significantly associated with perceived health. Perceived health was associated with race (whites thought they were healthier) and education (the college educated felt healthier).

- However, cycling was significantly associated with total physical activity measured by accelerometer along with sex (males were more active), race (whites more active), age (younger people more active), and car ownership (car owners less active).

- Cycling was also associated with lower body mass index along with education (with the college educated having lower BMIs) and home ownership.

That is people who cycled more miles per week had characteristics that are often seen to be associated with good health - they had lower BMls and were more active after controlling for confounding variables--but did not perceive their health to be better. But again, all associations are modest.

\section{INSERT TABLE 5 HERE}

Given the density relation was the strongest environmental factor associated with cycling, we test it in the regressions. When density (population + employment/area measured for a 400 m network buffer) is added to the regressions, it is significant in the perceived health and body mass index regression. Those in higher density areas perceived themselves as less healthy and were heavier. Adding in density does not alter which other variables are significant at the $p<0.05$ level in the various equations except that home ownership is no longer significantly associated with BMI. For the OLS regressions where $\mathrm{R}^{2}$ is a relevant measure of fit, the values are low, meaning that much of the variation in outcome variables (PA, body mass index, health) is not explained by the models.

\section{Discussion and Policy Implications}

This paper shows that in this study frequent and occasional cyclists were different from those who did not cycle regarding individual characteristics. They also differed to a modest extent in terms of the kinds of neighborhoods they lived in.

In relation to health related outcomes, compared with others frequent cyclists had lower BMIs and were more physically active overall. This was true after controlling for sex, race, education, marital status, home ownership, car ownership, age, household size, and density. This may not seem so surprising. However, given that accelerometers, used to measure total physical activity do not measure cycling very well this is not an automatic finding. It is possible that those who were already active in other domains chose to cycle as well.

After adjusting for socio-demographic variables cyclists, however, did not perceive themselves as healthier. It may be more useful to cast this finding in the opposite direction. Non-cyclists had characteristics typically seen as indicating poorer health-their BMIs were higher and they were less active. However they did not perceive themselves to be less healthy after controlling for socio-demographic confounders. This may be a barrier to increasing their 
activity through cycling or other means. This result is consistent with new work by Macmillan and colleagues (Macmillan et al. in press).

In terms of environmental features the most consistent association was with density, with those living in lower density areas cycling more. This can perhaps be explained by the situation that lower density environments have longer distances between destinations making cycling more viable than walking. In addition, one of the measures used in this study combined recreational and travel cycling, in part because purposes can be difficult to disentangle for cyclists. Evidence from the U.S. and Europe shows that recreational rides are often longer than transportation trips and it is possible that people in lower density areas ride more for recreation (lacono et al. 2008; Martens 2004; Xing et al. 2010). In contrast, non-cyclists lived in areas with higher densities, smaller blocks, and other features associated with walking for transportation such as more sidewalks. However, there were many insignificant results. These findings are similar to those of earlier studies that while finding some associations between cycling and the built environment, concluded that the characteristics of cyclists were more important than environment in predicting cycling (Moudon et al., 2005; Cervero et al., 2009; Noland et al., 2011).

This study has a number of limitations. In examining cycling and environments, this paper does not look specifically at the association between cycling and cycling-infrastructure such as bicycle lanes. This is because these were not measured; they may still be important and are certainly worthy of further study. Rather it looks at measures of overall community design such as density (a proxy for closeness of destinations), street network, mixed-use; along with more general infrastructure such as sidewalks, street lights, street trees, and traffic calming, finding few associations.

The study also uses a number of imperfect measures of cycling. These include the IPAQ that asked about cycling for more than 10 minutes at a time in the last week missing smaller bouts of cycling. The travel diary asked participants to list specific trips and their length in blocks or miles; respondents could have inaccurately recalled their activities or misestimated distances.

For those aiming to increase cycling this paper suggests some points of policy and planning intervention. In this light the study has identified an important group of occasional cyclists - they typically owned bicycles, had cycled in the past 2 years, but had not done so in the past week. Results in Table 3 show they lived in rather similar kinds of areas to more frequent cyclists-while non-cyclists lived in somewhat different kinds of places. Table 4 shows that they perceived the environment rather similarly to frequent cyclists as well. There are some important exceptions, however; e.g., they were rather closer to non-cyclists in terms of their perceptions of access to services and of places for walking and cycling. This group might well be persuaded to cycle more and this may be easier than persuading those who have not cycled in some time or have never cycled. Bonham and Wilson (2012) make a similar point about the opportunities to promote cycling in relation to women "returning" cyclists in Australia (als Akar et al., in press). This study suggests that social marketing programs might target the perceived environment-particularly the topics identified above (accessibility and general walkability and bikeability). 
As noted earlier however, merely increasing cycling does not necessarily increase overall physical activity if it substitutes for other kinds of activity such as walking. This is a key challenge for public health that may be answered in future longitudinal studies. 
Table 1: Frequent, Occasional, and Non-cyclists Compared

\begin{tabular}{|c|c|c|c|c|c|c|c|c|c|c|}
\hline & & $\begin{array}{r}\text { A. Frequent } \\
\text { Cyclist }^{\mathrm{a}}\end{array}$ & & $\begin{array}{l}\text { B. Occas. } \\
\text { Cyclist }^{\text {b }}\end{array}$ & & $\begin{array}{l}\text { C. Non } \\
\text { Cyclist }\end{array}$ & $A+B$ vs. $C^{c}$ & & $A$ vs. $B+C$ & \\
\hline & & $\% /$ Mean & & $\% /$ Mean & & $\% /$ Mean & & & test & \\
\hline & $\mathrm{N}$ & $(S D)$ & $\mathrm{N}$ & (SD) & $\mathrm{N}$ & $(S D)^{*}$ & test statistic & $\mathrm{p}$-value & statistic & $\mathrm{p}$-value \\
\hline Total & 73 & & 346 & & 284 & & & & & \\
\hline \multicolumn{11}{|l|}{ Physical Activity and Health } \\
\hline Cycling (diary miles/day) & 73 & $2.55(3.41)$ & 346 & $0(0)$ & 282 & $0(0)$ & $t=4.29 *$ & 0 & $t=-18.98^{*}$ & 0 \\
\hline Travel Walk (miles/day) & 72 & $0.60(1.20)$ & 346 & $0.44(0.79)$ & 282 & $0.44(0.93)$ & $t=0.64$ & 0.520 & $t=-1.25$ & 0.213 \\
\hline Total Walk (miles/day) & 72 & $1.03(1.32)$ & 346 & $0.85(1.19)$ & 283 & $0.79(1.18)$ & $t=1.15$ & 0.250 & $t=-1.25$ & 0.213 \\
\hline Cycling MET Minutes (IPAQ) ${ }^{\mathrm{d}}$ & 73 & $636(1297)$ & 346 & $25.9(168)$ & 282 & $0(0)$ & $t=3.66$ & 0 & $\mathrm{~T}=-12.15$ & 0 \\
\hline \multicolumn{11}{|l|}{ Accelerometer $(1000$} \\
\hline counts/day) & 73 & $267(127)$ & 344 & $235(91)$ & 281 & 199(98) & $t=5.37^{*}$ & 0 & $t=-3.93^{*}$ & 0 \\
\hline \multicolumn{11}{|l|}{ Overall perceived health $(5=$} \\
\hline excellent) & 73 & $3.88(0.80)$ & 345 & $3.75(0.84)$ & 282 & $3.48(0.98)$ & $\mathrm{t}=-4.29 *$ & 0 & $t=-2.20^{*}$ & 0.028 \\
\hline $\begin{array}{r}\text { Body Mass Index } \\
\text { Demographics }\end{array}$ & 74 & $26.60(4.55)$ & 334 & $28.14(6.16)$ & 273 & $29.06(7.42)$ & $t=-2.30^{*}$ & 0.021 & $t=2.15^{*}$ & 0.032 \\
\hline Men & 39 & 53 & 114 & 33 & 92 & 33 & $\chi^{2}=2.66$ & 0.265 & $\chi^{2}=11.94^{*}$ & 0.003 \\
\hline Caucasian & 64 & 88 & 289 & 83 & 222 & 78 & $\chi^{2}=3.54$ & 0.060 & $\chi^{2}=1.75$ & 0.186 \\
\hline College Degree & 45 & 62 & 160 & 46 & 111 & 39 & $\chi^{2}=6.08^{*}$ & 0.014 & $\chi^{2}=9.10 *$ & 0.003 \\
\hline Married & 50 & 69 & 211 & 61 & 150 & 53 & $\chi^{2}=5.62 *$ & 0.018 & $\chi^{2}=3.18$ & 0.075 \\
\hline Own Home & 57 & 79 & 277 & 80 & 191 & 68 & $\chi^{2}=12.93^{*}$ & 0 & $\chi^{2}=0.70$ & 0.404 \\
\hline Age & 73 & $47.4(13.6)$ & 346 & 44.8 (11.9) & 279 & $49.6(15.3)$ & $t=-4.06^{*}$ & 0 & $t=0.07$ & 0.941 \\
\hline Household Income $(x \$ 1,000)$ & 68 & $60.4(31.3)$ & 316 & $60.1(29.6)$ & 256 & $47.1(29.2)$ & $t=5.43^{*}$ & 0 & $t=-1.57$ & 0.116 \\
\hline Household size & 73 & $2.81(1.29)$ & 343 & $2.86(1.44)$ & 281 & $2.52(1.60)$ & $t=2.87^{*}$ & 0.004 & $t=0.57$ & 0.569 \\
\hline \multirow[t]{2}{*}{ Car Ownership (yes/no) } & 67 & 93 & 329 & 95 & 259 & 92 & $\chi^{2}=1.90$ & 0.168 & $\chi^{2}=0.06$ & 0.808 \\
\hline & & 11.01 & & $10.83(10.2$ & & & & & & \\
\hline Housing tenure in years & 73 & $(10.30)$ & 345 & 9) & 281 & $14.19(15.27)$ & $\mathrm{t}=-3.34^{*}$ & 0.001 & $t=-0.88 *$ & 0.379 \\
\hline
\end{tabular}

a Any miles in travel diary (last week)

b Ridden bicycle in neighborhood in past 2 years but not last week

c. These letters refer to the first letters in the column headings to the left of the table.

d. The IPAQ numbers are slightly different to the diary numbers: 12 people recorded cycling in the past week in the IPAQ survey but not in the diary.

* Significant at the $\mathrm{P}=<.05$ level 
Table 2: Statistically Significant Correlations of Cycling Distance with Environmental Features

\begin{tabular}{|c|c|c|}
\hline Variable & $\begin{array}{l}\text { IPAQ } \\
\text { Cycling(from } \\
\text { place to place) }\end{array}$ & $\begin{array}{l}\text { Total Cycling } \\
\text { Miles (all } \\
\text { purposes) } \\
\end{array}$ \\
\hline \multicolumn{3}{|c|}{ Population / Land Area } \\
\hline $200 \mathrm{~m}$ network & & $-0.09 *$ \\
\hline $400 \mathrm{~m}$ network & & $-0.09 *$ \\
\hline $200 \mathrm{~m}$ straight line & & $-0.08^{*}$ \\
\hline \multicolumn{3}{|c|}{ Population / Developed Land Area } \\
\hline $400 \mathrm{~m}$ network & & $-0.09 *$ \\
\hline $200 \mathrm{~m}$ straight line & & $-0.08 *$ \\
\hline \multicolumn{3}{|c|}{ Population + Employment / Land Area a } \\
\hline $400 \mathrm{~m}$ network & & $-0.09 *$ \\
\hline $200 \mathrm{~m}$ straight line & & $-0.08^{*}$ \\
\hline \multicolumn{3}{|c|}{ Housing Units / Unit Land Area (census data) } \\
\hline 200m network & & $-0.08 *$ \\
\hline 400m network & & $-0.08 *$ \\
\hline \multicolumn{3}{|c|}{ \% Parcel Area: Industrial } \\
\hline $400 \mathrm{~m}$ network & $0.08^{*}$ & \\
\hline \multicolumn{3}{|c|}{ \% Parcel Area: Parks/ Rec } \\
\hline $1600 \mathrm{~m}$ straight line & & $0.10 * *$ \\
\hline \multicolumn{3}{|c|}{ \% Parcel Area: Industrial and Auto-Oriented Uses } \\
\hline $400 m$ network & $0.08 *$ & \\
\hline \multicolumn{3}{|c|}{ Percent of Street Segments with Visible Litter, Graffiti, or Dumpsters ${ }^{a}$} \\
\hline $200 m$ network & $0.08^{*}$ & $0.08^{*}$ \\
\hline
\end{tabular}

* Significant at the $p<0.05$ level and ${ }^{* *}$ significant at the $p<0.01$ level. Note many other features were not significant.

a. Variable only measured for 200 and $400 \mathrm{~m}$ straight line and network buffers around participant residence due to data availability. 
Table 3: Environmental Variables with Significant Differences Between Types of Cyclists

\begin{tabular}{|c|c|c|c|c|c|c|c|c|}
\hline & & $\begin{array}{l}\text { A. Frequent } \\
\text { Cyclist }^{\mathrm{a}}\end{array}$ & & $\begin{array}{l}\text { B. Occas. } \\
\text { Cyclist }{ }^{\text {b }}\end{array}$ & & $\begin{array}{l}\text { C. Non } \\
\text { Cyclist }\end{array}$ & $\begin{array}{l}\text { A vs. } \\
\text { B vs. } \\
\text { C }\end{array}$ & \\
\hline & $\mathrm{N}$ & Mean (SD) & $\mathrm{N}$ & Mean (SD) & $\mathrm{N}$ & Mean $(S D)^{*}$ & $\mathrm{~F}$ & $\begin{array}{l}\mathrm{p} \text { - } \\
\text { value }\end{array}$ \\
\hline \multicolumn{9}{|l|}{ Density ${ }^{a}$} \\
\hline Population / Developed $\mathrm{Ha}$ & 76 & $24.6(12.1)$ & 346 & $24.5(12.3)$ & 282 & $27.2(12.2)$ & 4.18 & 0.015 \\
\hline $\begin{array}{l}\text { Population / HA } \\
\text { Population + Employment / }\end{array}$ & 76 & $18.3(7.8)$ & 346 & $18.1(8.0)$ & 282 & $20.0(7.7)$ & 4.14 & 0.016 \\
\hline $\begin{array}{l}\text { Land Area }{ }^{\mathrm{b}} \\
\text { Residential Population / }\end{array}$ & 76 & $33.1(20.5)$ & 346 & $35.0(20.5)$ & 282 & $40.5(22.3)$ & 6.59 & 0.002 \\
\hline Residential Parcel Area & 76 & $42.5(22)$ & 346 & $42.4(21.2)$ & 282 & $49.6(23.5)$ & 8.76 & 0 \\
\hline Lot Coverage ${ }^{b}$ & 76 & $20.0(7.6)$ & 345 & $20.3(6.7)$ & 282 & $21.9(6.4)$ & 4.66 & 0.01 \\
\hline $\begin{array}{l}\text { Street Pattern } \\
\text { Median Census Block Area } \\
\text { (HA) } \\
\text { Intersections per Unit Area } \\
\text { (raw intersections) (per } 100 \\
\text { ha) }\end{array}$ & 76 & $2.78(1.35)$ & 346 & $2.88(1.30)$ & 282 & $2.60(1.13)$ & 4.13 & 0.017 \\
\hline Median Perimeter of Block & 76 & $732(201)$ & 346 & $752(204)$ & 282 & $710(187)$ & 3.62 & 0.027 \\
\hline Mixed Use & & & & & & & & \\
\hline $\begin{array}{l}\text { \% Parcel Area: Industrial } \\
\% \text { Parcel Area: Industrial }\end{array}$ & 76 & $6.8(8.2)$ & 346 & $7.8(9.1)$ & 282 & $10.0(10.2)$ & 5.37 & 0.005 \\
\hline $\begin{array}{l}\text { and Auto-Oriented Uses } \\
\text { Proportion of Dissimilar }\end{array}$ & 76 & $3.4(5.0)$ & 346 & $4.1(5.8)$ & 282 & $5.4(6.4)$ & 5.38 & 0.005 \\
\hline $\begin{array}{l}\text { Land Uses Among Grid Cells } \\
\text { in an Area, Formula } 1(\%)\end{array}$ & 76 & $27.9(5.4)$ & 346 & $28.5(5.5)$ & 282 & $29.9(6.2)$ & 6.03 & 0.003 \\
\hline $\begin{array}{l}\text { Infrastructure } \\
\text { Sidewalk Length / Road }\end{array}$ & & & & & & & & \\
\hline $\begin{array}{l}\text { Length } \\
\text { Transit Stop }\end{array}$ & 76 & $111(104)$ & 346 & $114(110)$ & 282 & $136(110)$ & 3.7 & 0.025 \\
\hline Density(Stops/100ha) & 76 & $12.1(6.4)$ & 346 & $12.0(6.7)$ & 282 & $13.3(6.3)$ & 2.97 & 0.052 \\
\hline
\end{tabular}


Cycling

Table 4: Perceived Environments: Differences between Types of Cyclists

\begin{tabular}{|c|c|c|c|c|c|c|c|c|}
\hline & \multirow[b]{2}{*}{$\mathrm{N}$} & \multirow{2}{*}{$\begin{array}{l}\text { A. Frequent } \\
\text { Cyclist }^{\text {a }} \\
\text { Mean (SD) }\end{array}$} & \multirow[b]{2}{*}{$\mathrm{N}$} & \multirow{2}{*}{$\begin{array}{l}\text { B. Occas. } \\
\text { Cyclist }^{\mathrm{b}} \\
\text { Mean (SD) }\end{array}$} & \multirow[b]{2}{*}{$\mathrm{N}$} & \multirow{2}{*}{$\begin{array}{l}\text { c. Non } \\
\text { Cyclist } \\
\text { Mean (SD)* }\end{array}$} & \multicolumn{2}{|c|}{ A vs. B vs. C } \\
\hline & & & & & & & $\mathrm{F}$ & $\begin{array}{c}\mathrm{p}- \\
\text { value }\end{array}$ \\
\hline $\begin{array}{r}\text { Access to services (6 } \\
\text { items) })^{1,2,3}\end{array}$ & 69 & $2.96(0.47)$ & 330 & $2.80(0.51)$ & 273 & $2.76(0.50)$ & 4.41 & 0.013 \\
\hline $\begin{array}{r}\text { Places for walking and } \\
\text { cycling ( } 3 \text { items })^{2,} \\
\text { Neighborhood } \\
\text { surroundings/ }\end{array}$ & 61 & $3.30(0.54)$ & 295 & $3.13(0.66)$ & 241 & $3.07(0.68)$ & 3.06 & 0.048 \\
\hline $\begin{array}{l}\text { attractiveness (6 items) }{ }^{2} \\
\text { Safety from traffic (2 }\end{array}$ & 61 & $3.36(0.41)$ & 292 & $3.25(0.49)$ & 242 & $3.09(0.60)$ & 9.26 & 0.000 \\
\hline $\begin{array}{r}\text { items }^{2}, \\
\text { Safety from crime (6 }\end{array}$ & 72 & $3.11(0.75)$ & 343 & $3.05(0.79)$ & 282 & $3.02(0.79)$ & 0.40 & 0.673 \\
\hline $\begin{array}{r}\text { items) } \\
\text { Neighborhood }\end{array}$ & 70 & $3.22(0.48)$ & 337 & $3.17(0.48)$ & 266 & $3.03(0.55)$ & 7.35 & 0.001 \\
\hline $\begin{array}{r}\text { satisfaction (16 items) }{ }^{4,5} \\
\text { Social cohesion of }\end{array}$ & 38 & $3.72(0.56)$ & 207 & $3.71(0.64)$ & 134 & $3.49(0.62)$ & 4.85 & 0.008 \\
\hline $\begin{array}{l}\text { Neighborhood (5 items) }{ }^{6} \\
\text { Social life/neighboring (9 }\end{array}$ & 72 & $2.85(0.38)$ & 341 & $2.85(0.44)$ & 271 & $2.85(0.46)$ & 0.02 & 0.981 \\
\hline items) $^{7}$ & 76 & $5.75(4.10)$ & 345 & $5.65(4.20)$ & 282 & $4.42(3.51)$ & 8.53 & 0.000 \\
\hline $\begin{array}{r}\text { Social life/collective } \\
\text { action ( } 8 \text { items) }^{6}\end{array}$ & 76 & $2.22(0.53)$ & 344 & $2.22(0.69)$ & 279 & $2.30(0.69)$ & 1.24 & 0.289 \\
\hline
\end{tabular}

1. To construct scales, relevant items have been reversed so that all are in the same direction with higher numbers being better.

2. Responses are four points 1 strongly agree to 4 strongly disagree.

3. Section prefaced with: "Please choose the answer that best applies to you and your neighborhood. Both local and within walking distance mean within a 20 minute walk from your home." Scales are from survey sections $\mathrm{H}, \mathrm{I}$, J, K, L, and M (Twin Cities Walking Survey 2005).

4. Responses are 1 strongly dissatisfied to 5 strongly satisfied.

5. $\mathrm{N}$ is low because a number of people did not answer questions related to cycling and schools.

6. Scale is 5 points from $1=$ strongly disagree to $5=$ strongly agree.

7. Scale is average number of days in the past month participants have done each activity. 
Table 5: Regression Results of Health Outcome Measures Relative to Miles Cycled

\begin{tabular}{|c|c|c|c|c|c|c|}
\hline & $\begin{array}{r}\text { Adjusted } \\
\text { model }\end{array}$ & & & $\begin{array}{r}\text { Adjusted } \\
\text { model } \\
\text { with } \\
\text { density }\end{array}$ & & \\
\hline $\begin{array}{r}\text { Outcome } \\
\text { Measure } \\
\text { (across) }\end{array}$ & $\begin{array}{r}\text { Perceived } \\
\text { health }\end{array}$ & Total PA & $\begin{array}{r}\text { BMI } \\
\text { (measure } \\
\text { d) }\end{array}$ & $\begin{array}{r}\text { Perceived } \\
\text { health }\end{array}$ & Total PA & $\begin{array}{r}\text { BMI } \\
\text { (measure } \\
\text { d) }\end{array}$ \\
\hline Miles cycled & 0.003 & $0.007^{*}$ & $-0.038^{*}$ & 0.002 & $0.007^{*}$ & $-0.033^{*}$ \\
\hline Male & 0.113 & $0.125^{*}$ & -0.116 & 0.12 & $0.126^{*}$ & -0.164 \\
\hline Race (white) & $0.310^{*}$ & $0.173 *$ & 0.781 & 0.284 & $0.172 *$ & 0.959 \\
\hline College degree & $0.468 *$ & 0.06 & $-2.293^{*}$ & $0.541^{*}$ & 0.06 & $-2.159 *$ \\
\hline Married & 0.111 & 0.002 & -1.094 & 0.096 & 0.002 & -0.986 \\
\hline Home owner & 0.074 & 0.083 & $-1.568^{*}$ & 0.000 & 0.081 & -1.003 \\
\hline Car owner & 0.045 & $-0.186^{*}$ & -1.258 & 0.015 & $-0.187^{*}$ & -1.015 \\
\hline Age & -0.001 & $-0.007 *$ & 0.035 & -0.002 & $-0.007^{*}$ & 0.041 \\
\hline $\begin{array}{r}\text { Household } \\
\text { size }\end{array}$ & 0.025 & -0.001 & 0.253 & -0.024 & -0.001 & 0.262 \\
\hline $\begin{array}{r}\text { Density } \\
\text { (population + } \\
\text { employment) }\end{array}$ & & & & -0.006 & -0.000 & $0.040 *$ \\
\hline Constant & $2.975^{*}$ & $12.54^{*}$ & $29.512^{*}$ & $3.307^{*}$ & $12.551^{*}$ & 27.029 \\
\hline R-squared & 0.129 & NA & 0.074 & 0.136 & NA & 0.081 \\
\hline
\end{tabular}

Note: Models regress miles cycled on outcome variables and are adjusted for sex, race, education, marital status, home ownership, car ownership, age, and household size. Refined models added density (Population + Employment / Land Area measured for a 400 m network buffer).

Effects for physical activity outcome is non-exponentiated coefficients from negative binomial regressions; effects for remaining outcomes are coefficients from linear regressions. All models account for clustering by 36 neighborhoods.

a. Measured by accelerometer.

* Significant at the $p<0.05$ level. 


\section{Acknowledgements}

We would like to thank the editor and three anonymous reviewers for very helpful comments. Sam Liu provided initial statistical research assistance; Kathryn H. Schmitz worked on measurement; and Kevin Krizek provided valuable comments on an earlier draft.

\section{Funding}

The Active Living Research program of the Robert Wood Johnson Foundation funded the original study.

\section{References}

Akar, G, Fischer, N, Namgung, M. In press. Bicycling choice and gender case study: The Ohio State University. International Journal of Sustainable Transportation, DOI:10.1080/15568318.2012

Bassett, DR, Pucher J, Buehler R, Thompson DL, Crouter SS. 2008. Walking, cycling, and obesity rates in Europe, North America, and Australia. Journal of Physical Activity and Health 5: 795-814.

Boarnet M, Day K, Alfonzo M, Forsyth A, Oakes JM. 2006. The Irvine Minnesota Inventory to measure built environments: reliability tests. American Journal of Preventive Medicine, 30, 2: 153-259.

Bonham, J, Wilson, A. 2012 Bicycling and the life course: the start-stop-start experiences of women cycling. International Journal of Sustainable Transportation, 6, 4: 195-213.

Centers for Disease Control and Prevention. 2006a. Physical Activity for Everyone: Measuring Physical Activity Intensity: Metabolic Equivalent (MET) Level. http://www.cdc.gov/nccdphp/dnpa/physical/measuring/met.htm

Centers for Disease Control and Prevention. 2006a. U.S. Physical Activity Statistics: Definitions. http://www.cdc.gov/nccdphp/dnpa/physical/measuring/met.htm

Cervero R, Sarmiento O, Jocoby E, Gomez LF, Neiman A. 2009. Influences of built environments on walking and cycling: lessons from Bogota. International Journal of Sustainable Transportation 3, 4: 203-226.

Cervero R, Duncan M. 2003. Walking, bicycling, and urban landscapes: Evidence from the San Francisco Bay Area. American Journal of Public Health 93, 9: 1478-1483.

Day K, Boarnet, M, Alfonzo M, Forsyth A. 2006 The Irvine Minnesota Inventory to measure built environments: development, American Journal of Preventive Medicine 30, 2: 144-152.

Dill J, Voros K. 2007. Factors affecting bicycling demand: Initial survey findings from the Portland, Oregon, region. Transportation Research Record2031:9-17.

Dill J. 2009. Bicycling for transportation and health: The role of infrastructure. Journal of Public Health Policy 30: S95-S110.

Forsyth A, Hearst M, Oakes JM, Schmitz MK. 2008. Design and destinations: factors influencing walking and total physical activity. Urban Studies 45, 9: 1973-1996.

Forsyth A. ed. 2005. Environment and Physical Activity: GIS Protocols. Version 3.0 http://www.designforhealth.net/resources/gis protocols.html 
Forsyth A, Krizek K. 2010. Promoting walking and bicycling: assessing the evidence to assist planners. Built Environment 36, 4: 429-446.

Forsyth A, Oakes JM, Schmitz KH, and Hearst M. 2007. Does residential density increase walking and other physical activity? Urban Studies 44, 4: 679-697.

Forsyth A, Oakes JM, Schmitz KH. 2009. Test-retest reliability of the Twin Cities walking survey. Journal of Physical Activity and Health 6, 1: 119-131.

Giles-Corti B, Donovan R. 2002. The relative influence of individual, social and physical environment determinants of physical activity. Social Science and Medicine 54, 12: 17931812.

Handy S. 2005. Critical assessment of the literature on the relationships among transportation, land use, and physical activity. Transportation Research Board and the Institute of Medicine Committee on Physical Activity, Health, Transportation, and Land Use. Resource paper for TRB Special Report (282):Does the Built Environment Influence Physical Activity? Examining the Evidence.

Handy S, Xing Y. 2010. Factors correlated with bicycle commuting: A study in six small U.S. cities. International Journal of Sustainable Transportation 5, 2: 91-110.

Heinen E, van Wee B, Maat K. 2010. Commuting by bicycle: an overview of the literature. Transportation Review 30, 1: 59 - 96.

Heinen A, Handy S. 2012. Similarities in attitudes and norms and the effect on bicycle commuting: evidence from the bicycle cities Davis and Delft. International Journal of Sustainable Transportation 6, 5: 257-281.

lacono M, Krizek K J, El-Geneidy A. 2008 Access to destinations: how close is close enough? estimating accurate distance decay functions for multiple modes and different purposes. Report MN/RC 2008-11 Minnesota Department of Transportation, St. Paul, MN.

Jacobsen PL. 2003. Safety in numbers: more walkers and bicyclists, safer walking and cycling. Injury Prevention 9: 205-9.

Kamphuis CB, Giskes K, Kavanagh AM, Thornton LE, Thomas LR, van Lenthe FJ, Mackenbach JP, Turrell G, 2008. Area variation in recreational cycling in Melbourne: a compositional or contextual effect? Journal of Epidemiology and Community Health 62, 890-898.

Krizek K, Handy S, Forsyth A. 2009. Explaining changes in walking and bicycling behavior: challenges for transportation research. Environment and Planning B 36: 725-740.

Macmillan R, Duke N, Oakes JM, Liao W, In Press. Trends in the association of obesity and selfreported overall health in 30 years of the integrated health interview series. Obesity.

Martens K. 2004. The bicycle as a feedering mode: experiences from three European countries. Transp. Res. Part D 9, 4: 281-294.

McLeroy KR., Bibeau D, Steckler A, Glanz K. 1988. An ecological perspective on health promotion programs. Health Education Quarterly 15, 4: 351-377.

Moudon A V, Lee C, Cheadle AD, Collier CW, Johnson D, Schmid TL, Weather RD. 2005. Cycling and the built environment, a U.S. perspective. Transportation Research Part D 10: 245-261.

Noland RB, Deka D, Walia R. 2011. A statewide analysis of bicycling in New Jersey. International Journal of Sustainable Transportation 5, 5: 251-269. 
Oakes JM, Forsyth A, Schmitz KH. 2007. The effect of neighborhood density and street connectivity on walking behavior: The Twin Cities walking study. Epidemiologic Perspectives \& Innovations 4, 16: http://www.epi-perspectives.com/content/4/1/16/abstract

Oakes JM, Forsyth A, Hearst M, Schmitz KH. 2009 Recruiting a Representative Sample for Neighborhood Effects Research: Strategies and Outcomes of the Twin Cities Walking Study. Environment and Behavior 41, 6: 787-805.

Owen, N., De Bourdeaudhuij, I., Sugiyama, T., Leslie, E., Cerin, E., Van Dyck, D. \& Bauman, A. 2010. Bicycle use for transport in an Australian and a Belgian city: associations with built-environment attributes, Journal of Urban Health 87: 189-98.

Pucher J, Dill J, Handy S. 2010. Infrastructure, programs, and policies to increase bicycling: An international review. Preventive Medicine 50: S106-S125.

Rodriguez D, Khattak AJ, Evenson K. 2006. Can new urbanism encourage physical activity? Journal of the American Planning Association 72, 1: 43-54.

Sirard J Forsyth A, Oakes JM , Schmitz K H. 2011. Accelerometer Test-Retest Reliability by Data Processing Algorithms: Results from the Twin Cities Walking Study. Journal of Physical Activity and Health 8, 5: 668-674.

Stokols D 1992. Establishing and maintaining healthy environments: Toward a social ecology of health promotion.. American Psychologist, 47, 1: 6-22.

Twin Cities Walking Survey. 2004. http://www.activelivingresearch.org/files/TwinCityWalkingSurvey.doc

Wells NM, Ashdown SP, Davies EHS, Cowett FD, \& Yang Y 2007. Environment, design, and obesity: opportunities for interdisciplinary collaborative research. Environment and Behavior 39, 1: 6-33.

Wen LM, Rissel C. 2009. Inverse associations between cycling to work, public transport, and overweight and obesity: Findings from a population based study in Australia. Preventive Medicine 46: 29-32.

Xing Y, Handy S, Mokhtarian P. 2010. Factors associated with proportions and miles of bicycling for transportation and recreation in six small U.S. cities. Transportation Research Part D 15: 73-81.

Yang L, Sahlqvist S, McMinn A, Griffin S, Ogilvie D. 2010. Interventions to promote cycling: systematic review. British Medical Journal 341: c5293. 